\title{
Mental Health Education for Students from Junior Colleges Moving into Undergraduate Level in Private Colleges from the Perspective of Three- Dimensional Education
}

\author{
Mei Chen*, Jiaojiao Li \\ Guangzhou Huashang College, Guangzhou 511300, Guangdong Province, China \\ *Corresponding author: Mei Chen, luotan399317@163.com
}

\begin{abstract}
Good psychological quality is the basic requirement for college students in the new era. Students from junior colleges moving into undergraduate level in private colleges are a special group as they are already an important part of students in private colleges. Based on the mental health status of these students, private colleges have analyzed the issues of mental health education which include weak teaching staffs, lack attention, and traditional education methods. From the perspective of three-dimensional education, the psychological education work model in private colleges is explored to build an education team to promote the participation of all employees in the work of psychological education, strengthen the attention of college students who are moving into the undergraduate level, and to pay full attention to these students. Private colleges should try to innovate education methods and improve psychological education in all aspects.
\end{abstract}

Keywords: Three-dimensional education; Private colleges; College students moving into undergraduate level; Mental health education

Publication date: August 2021; Online publication: August 30, 2021

\section{Introduction}

In recent years, with the popularization of higher education, private colleges have continuously expanded their enrollment and the number of college students moving into the undergraduate level has continued to increase. This has become an important aspect in private colleges. These students from private colleges have their own characteristics; hence, the focus of mental health education is on how to effectively carry out mental health education according to their psychological characteristics. Private colleges should combine the mental health status of these students to explore the psychological education work model in private colleges from the perspective of three-dimensional education to improve the effectiveness of mental health education.

\section{Mental health status of college students moving into the undergraduate level in private colleges}

\subsection{Research subject}

A total of 1989 students who joined a private college in 2020 were selected as research subjects. The test was conducted in mid and late October after their enrollment. Among them, 1978 students participated in the test where 775 were boys and 1203 were girls with a participation rate of $99.45 \%$. 


\subsection{Test tools}

The Symptom Self-Rating Scale (SCL-90) was used as a psychometric tool with a total of 90 questions and 10 factors. The five-level scoring method was used in this scale. According to the national norm, a total score greater than or equal to 160 points or any factor score exceeding 2 points indicated a positive result which was considered as the existence of a certain degree of psychological problems ${ }^{[1]}$.

\subsection{Test procedures and statistical methods}

The school's psychological survey leading group convened a meeting with the counselor before the test to clarify the purpose and significance of the psychological survey, maintain the responsibilities of all parties, as well as notify and publicize them to ensure that the psychological survey would be carried out in an orderly and effective manner. The Mental Health Education and Counseling Center of the school conducted training and pre-testing for test staffs, unified the instructions and test procedures, as well as ensured that the on-site test staffs understood and mastered the test procedures. In the formal test, the class was taken as a unit and the Lexus Dynamic Mental Health Early Warning System was used to conduct a centralized evaluation in the computer room.

After the test, Ling Dynamic Mental Health Treatment Early Warning System was used for data collection and statistical arrangements. Statistical Package for the Social Sciences (SPSS) version 19.0 software was used for descriptive statistics and variance analysis.

\subsection{Results}

The total scores from the students' Symptom Self-rating Scale reached an average value of 113.21 \pm 29.56 . There were 375 people with positive symptoms, and the rate of it was $18.96 \%$. The results showed that most of these students' mental health was good but some students had a certain degree of psychological problems.

The SCL-90 screening results of 1978 students showed that there were 375 people with positive symptoms where 131 were boys and 244 were girls in which the detection rates were $16.9 \%$ and $20.28 \%$, respectively. This was higher than the overall detection rate in comparison to all the students who entered college in 2020. The total score of the girls was significantly higher than that of the boys, and there was a statistically significant difference. Except for hostility, paranoia, and psychosis, other factors had significant differences as shown in Table 1. This suggested that the key population of mental health education is made up of female students. The possible reasons are that the numbers of female students in the economics and management department of private colleges are far more than male students with a ratio of 6:4 and under the influence of biological factors, female students are more sensitive than their male counterparts where they pay more attention to their inner emotional experiences. In addition, it is easier for them to develop negative emotions such as anxiety, tension, and depression when coping with various life events ${ }^{[2]}$. 
Table 1. Comparison of gender differences in SCL-90 factors among students from junior college to the undergraduate level in private college $(\mathrm{x} \pm \mathrm{s}$, points)

\begin{tabular}{ccccc}
\hline Factor & Boys $(\mathbf{n}=\mathbf{7 7 5})$ & Girls $(\mathbf{n = 1 2 0 3})$ & t value & P value \\
\hline Somatization & $1.14 \pm 0.29$ & $1.18 \pm 0.28$ & -3.325 & $0.001^{* *}$ \\
Force & $1.42 \pm 0.49$ & $1.51 \pm 0.47$ & -3.906 & $0.000^{* *}$ \\
Interpersonal relationship & $1.29 \pm 0.44$ & $1.33 \pm 0.41$ & -2.487 & $0.013^{*}$ \\
Depression & $1.22 \pm 0.38$ & $1.30 \pm 0.40$ & -4.353 & $0.000^{* *}$ \\
Anxiety & $1.20 \pm 0.36$ & $1.28 \pm 0.38$ & -4.762 & $0.000^{* *}$ \\
Hostility & $1.19 \pm 0.37$ & $1.21 \pm 0.32$ & -1.41 & 0.159 \\
Horror & $1.13 \pm 0.30$ & $1.21 \pm 0.32$ & -5.637 & $0.000^{* *}$ \\
Paranoid & $1.20 \pm 0.38$ & $1.22 \pm 0.33$ & -1.057 & 0.29 \\
Psychotic & $1.19 \pm 0.36$ & $1.20 \pm 0.30$ & -1.002 & 0.317 \\
Other & $1.26 \pm 0.39$ & $1.30 \pm 0.38$ & -2.319 & $0.021^{*}$ \\
Total & $110.25 \pm 30.40$ & $115.12 \pm 28.86$ & -3.588 & $0.000^{* *}$ \\
\hline
\end{tabular}

Note: $* \mathrm{P}<0.05, * * \mathrm{P}<0.01$

\section{Inadequacy of mental health education for students in private colleges}

According to the survey results, most of the junior college students had good mental health but some students had a certain degree of psychological problems. This means that schools should pay attention to college students' mental health education. However, private colleges have some shortcomings in their actual work.

\subsection{Weak faculty}

Issues such as welfare benefits, high liquidity of teachers, and unstable faculty have always been a problem for private colleges. At present, the main people who are engaged in the mental health education of private colleges are counselors and mental health education teachers in which they are seriously under-equipped. There is a shortage of counselors in private colleges and the number of students far exceeds 200 that is required by the document. The counselors are exhausted in all matters related to students such as the development of academic style, scholarships, student subsidies and loans, etc. They also serve as instructors for student organizations such as the general league branch, student union, and party branch. Sometimes, they are unable to fully understand the psychological condition of students and it is difficult to carry out indepth as well as detailed heart-to-heart talk activities. In many cases, when students come across serious psychological problems, counselors begin to pay attention to their psychological conditions and provide psychological counseling. Compared with other full-time teachers, counselors in private colleges have a higher liquidity. New counselors are often graduate students who have just graduated from universities. There are fewer counsellors with a background in psychology. They also have insufficient knowledge and practical experience in psychology, making it difficult to deal with complex psychological problems. On the other hand, there is also an inadequate number of mental health education teachers where it is difficult to meet the requirements of 1:4000. The number of students with psychological problems in private colleges has been increasing with modernization. At present, the focus of mental health education in private colleges is on students with psychological problems. Full-time staffs that are engaged in mental health education are busy with crisis intervention and subsequent follow-up consultations for students with psychological problems. They have no extra time to care for the students who are mentally normal. Colleges should adhere to the principle of prevention first, pay attention to students' daily psychological dynamics, and attach 
importance to the popularization of mental health knowledge so that students can consciously maintain their mental health and improve their mental health awareness. Mental health education in colleges should not only pay attention to mental health education for students with mental problems but they should also emphasize on the development of mental health education for students with normal mentality.

At present, the work of various functional departments in private colleges is independent and separated without any joint force. Students' activities are usually in classrooms, dining halls, dormitories, etc. where class teachers and dormitory administrators do not really participate in mental health education work. It is not enough to solely rely on counselors and full-time healthcare professionals to carry out mental health education work, but it requires the joint efforts of various functional departments in the school. Only then can they coordinate with each other and form a joint force in order to do a good job in the mental health education work ${ }^{[3]}$.

\subsection{Lack attention}

Private colleges attach great importance to psychological adaptation education for freshmen where various activities such as lectures of psychological adaptation, psychological evaluation, cardiac management health education are compulsory for freshmen. Students from junior colleges moving into the undergraduate level are very different from freshmen. As soon as they enter, they would begin at the third year of the undergraduate course. They are regarded as junior students and would start classes according to the teaching plans after enrollment. However, their teaching plans are not arranged with mental health education. There is also no adaptive education during the stage of enrollment. Only psychological assessment after enrollment is carried out during spare time. Even by the second semester of the junior year and the senior year, there are no psychological surveys with only a few psychological lectures and mental health activities. The management and service staffs in the school have weak mental health education awareness for collegeupgraded students. They assume that after three years of college education, these students are familiar with the learning environment in colleges and have a relatively matured mind, easily adapt to college life, and have good psychological adjustment capabilities. However, the results of a psychological survey in 2020 showed that the detection rate of positive symptoms among junior college students is $18.96 \%$. Combined with daily psychological consultation and psychological crisis intervention cases, the psychological crisis intervention cases for college-upgraded students are no less than that of the freshmen in addition to their year-by-year increase. Human psychology is a dynamic process. One psychological survey is difficult to accurately grasp the mental health of students. Many times, college-upgraded students have psychological problems in their previous colleges or even high schools. After they enter college, they would think that their situation has improved and eventually pay less attention to psychological adjustments. However, if they do not take the medications according to their doctor's prescription, they would easily relapse when they encounter some kind of pressure. Once the recurrence progresses, some even suspend or drop out of school. All the above-mentioned remind college educators to increase the attention on college-upgraded students.

\subsection{Traditional education method}

Private colleges often provide psychological counseling, mental health lectures, mental health education activities, and other psychological education work for all students with a typical universal characteristic. But there are a few contents that adapt to the actual psychological needs of college-upgraded students. Psychological activities mainly comprise of games in which this method is traditional and single. It is often a formality, and it is difficult to reflect the effect of psychological education in this way. With the new era, internet information is extremely developed. Most college-upgraded students are born after the year of 2000. 
As aborigines of the internet, they have strong ability to master new technologies, able to search for information quickly, have outstanding personalities, strong self-esteem, and they attach great importance to personal psychological experiences. However, since the starting point of college-upgraded students is lower than the ordinary undergraduates and they are relatively older, they are prone to have negative emotions such as inferiority and anxiety. They would face the pressure of employments and choosing careers after entering the new environment. Traditional mental health education is difficult to meet the psychological needs of these students. Hence, this requires a diversification of mental health education, abundant contents, and a constant innovation in the way of education.

\section{Psychological education work model for college-upgraded students in private colleges from the perspective of three-dimensional education}

\subsection{Building an education team and promoting the participation of all employees in psychological education}

In the process of deepening psychological education, teachers play a key role. With the popularization of higher education, the numbers of college-upgraded students in private colleges have been increasing. In order to do a good job in psychological education, it is necessary to have adequate teachers, namely the counselors and mental health educators in accordance with the requirements of the document to solve the dilemma of "you can't make bricks without straw." If it is indeed not fully equipped, part-time staffs can be used to ensure the smooth progress of psychological education. In addition, school leaders should attach importance to mental health education and mobilize all employees to participate in psychological education in order to create an atmosphere where all employees engage in education. The main task of students is learning whereas full-time teachers take on the main role of teaching. Their daily teaching philosophy, attitude, and management affect the psychological growth of students. What more, students' main place of living is the dormitory; hence, the management attitude, philosophy, and behaviors of dormitory administrators subtly affect their mental health. Colleges should strengthen the training of all faculty and staffs in order for them to master the knowledge and methods of psychology, consciously integrate the concept of psychological education into daily teaching and management services, take the initiative to care for the growth of students, carefully discover students' psychological problems, and use psychological concepts in time to effectively guide students so as to solve problems from the bud and eventually help students to grow into talents of the motherland.

The backbone of student psychology is an important supplementary force for mental health education. Private colleges have student backbone teams such as mental health organization cadres, psychological committees, and dormitory psychological informants. They can take advantage of the time, space, and emotions of the students' psychological backbone to give full play to the subjective initiative of students and help in the psychological education work. In daily work, they can combine the publicity and popularization of mental health knowledge with the investigation of psychological problems as well as the prevention of psychological crises and the handling of emergencies while focusing on key groups and fully grasping the mental health of students. Once psychological problems are discovered, psychological committees and dormitory psychological informants can report it to the counselors in time. After receiving feedbacks from these students, these counselors would have fully grasp the information of the students with psychological problems, their best friends, roommates, class leaders, etc., and use the psychological concepts they have learned to provide psychological counseling to these students in time. When coming across complex psychological problems that cannot be solved, students can seek help from the school's mental health teachers, actively communicate and coordinate with their parents, and cooperate with each other while jointly seeking solutions in helping students tide over their psychological crisis ${ }^{[4]}$. 


\subsection{Strengthening the attention on college-upgraded students and paying full attention to them}

The numbers of college-upgraded students in private colleges have been increasing year by year along with frequent psychological crisis cases among them. The management and service staffs of schools have paid much more attention to their mental health education in addition to strengthening the attention on students from junior colleges moving into the undergraduate level. When enrolling in colleges, a comprehensive psychological assessment is carried out and counselors would then conduct a detailed heart-to-heart talk with students who have positive symptoms. For students with suicidal thoughts, the school's mental health center would take the initiative to arrange interviews and conduct investigations. The students' psychological problems would be promptly guided and thereafter, there would be follow-up visits. If students have serious psychological problems, they should actively communicate with their parents with timely referral to hospitals for professional diagnosis and treatment in addition to the supervision and encouragement by the schools in urging students to embrace life and learning with a healthy and positive attitude. In order to fully understand the mental health status of college-upgraded students, the mental health education of these students would be carried out in a targeted manner where psychological assessment work would be conducted again before their graduation from colleges in order to form a complete mental health file. Mental health education for these students goes through the whole process of cultivating the concept in launching the overall layout from enrollment to graduation. This mainly focuses on six periods which include after enrollment, before and after graduation, before and after examinations, before and after the beginning of college life, before and after the change of seasons, and before and after major events in order to observe and provide feedbacks on the psychological status of students in different periods as well as to carry out corresponding mental health education work according to the characteristics of students in different periods.

\subsection{Innovative ways of education and improving the work of psychological education in an all- rounded way}

A variety of mental health activities can be developed based on the psychological needs of college-upgraded students. For example, when they have just started at a new college, "heart-to-heart communication" psychological seminars can be organized to promote communication between classmates, enhance their feelings, and build a friendly class atmosphere. Other than that, career planning, dormitory relations, and life education can be organized during the second semester of the junior year. A series of seminars on employment psychology, emotional management psychological salons, group psychological counseling activities, etc. before graduation can also be conducted to train college-upgraded students' self-esteem, selfconfidence, and self-improvement in guiding them to face challenges with a healthy attitude and effectuating positive actions to overcome difficulties. According to the results of the psychological evaluation, girls' mental health is lower than boys. Mental health activities must be carried out in an allrounded way whereby guidance for girls should be strengthened in encouraging them to face life and learning with rational and peaceful attitudes.

With the help of new media, mental health education can be innovative. College-upgraded students are in the era of advanced internet where they have distinctive personalities and easy acceptance of new things. Colleges can make use of new media platforms such as WeChat official account, QQ, Douyin, etc. to innovate working methods. Online and offline methods can be used to popularize mental health knowledge, carry out psychological salons, and group psychological quality development activities to stimulate the interest of college-upgraded students in learning psychology, improve their psychological quality in an allrounded way, and enhance the effectiveness of psychological education. 


\section{Disclosure statement}

The authors declare that there is no conflict of interest.

\section{References}

[1] Mao F, Min M, Li J, 2000, Preliminary Evaluation of Graduate Mental Health. Journal of Health Psychology, 1: 36-8.

[2] Zhou Y, 2021, Analysis on the Mental Health Status of Freshmen in Private Colleges Based on Psychological Census under the "Four in One" Psychological Education Mode. Industry and Technology Forum, 20(03): 108-10.

[3] Wang J, 2021, Analysis of the Plight and Countermeasures of the Psychological Health Education of Private College Students under the Background of Three-Dimensional Education. Educational Science of Chinese Academy of Management Science Research Institute, :3.

[4] Chi C, Yu B, Guo Y, 2020, Construction of Mental Health Education Mode in Colleges and Universities under the Concept of Three-Dimensional Education. Journal of Chuzhou University, 22(03): 88-91, 95. 